\title{
APPLICATION OF THE AHP-TOPSIS-2N HYBRID METHOD FOR SELECTION OF AN ATTACK HELICOPTER TO BE ACQUIRED BY THE BRAZILIAN NAVY
}

\begin{abstract}
This paper aims to apply the hybrid method AHP-TOPSIS-2N for the selection of an attack helicopter to be acquired by the Brazilian Navy. Six helicopter models, among the most used by the Armed Forces of developed countries, were compared. The selected helicopter would be employed in the fire support required by the Brazilian Marine Corps Amphibious Operations. The helicopters had seven criteria - maximum speed, payload, number of rockets, number of air-to-ground missiles, range, main cannon and amount of ammunition for the guns - evaluated by airship officers of the Brazilian Navy. The application of the method presented two lists of ordering and prioritization of the helicopters as result, providing a richer and more robust sensitivity analysis, which provides security, transparency and simplicity to the decision-making process. After the application of the method, the AH-64E APACHE and MI-35M helicopters were chosen as the most suitable to be acquired.
\end{abstract}

Keywords: AHP-TOPSIS-2N; Multicriteria Analysis; Decision-making process; Brazilian Navy; Aircraft.

\section{Introduction}

Approved by Decree No. 6,703 of December 18, 2008, the National Defense Strategy (NDS), which was updated in 2012, aims to ensure the security of Brazil both in peacetime and in crises, establishing guidelines for the proper preparation and training of the Brazilian Armed Forces (AF).

Even in times of peace, it is essential that Brazil has modern $\mathrm{AF}$, equipped and trained to guarantee its sovereignty and strategic interests, and that support its foreign policy and positions in international forums.

The NDS provides, under the leadership of the Ministry of Defense, the acquisition of transport helicopters, reconnaissance and attack, acquired with commercial, industrial and technological compensation. Considering this need, due to the quantity, diversity and complexity of existing models today, the task of selecting an aircraft that is more appropriate to BN's needs, aiming to provide support to the operations performed by the Brazilian Marine Corps, is not simple at all.

This paper aims, therefore, to apply the hybrid method AHP-TOPSIS-2N to support the decision-making process for the acquisition of the best attack helicopters to be acquired by the $\mathrm{BN}$. 
ISAHP Article: A Style Guide for Individual Papers To Be Submitted to the International Symposium of the Analytic Hierarchy Process 2020, Web Conference.

\section{Literature Review}

The AHP-TOPSIS-2N method, initially proposed by Souza et al. (2018), consists of two Multicriteria Decision-Making (MCDM) techniques that are usually adopted in complex scenarios: AHP (Saaty, 1980) and TOPSIS (Hwang and Yoon, 1981) methods.

According to Souza et al. (2018), this methodology has the following advantages:

- Possibility of identifying the standard of the AHP-TOPSIS;

- The possibility of two coherent standardizations, which allows a sensitivity analysis of the Result;

- This sensitivity analysis allows to generate decision rules to group the alternatives into sets;

- The concept of hierarchy with weights associated with the conception of checking how much an alternative is closer and farther from an ideal solution.

\section{Hypotheses/Objectives}

Among the types of tactical necessary for carrying out aeronaval missions, we highlight the use of attack helicopters, suitable for reconnaissance and air fire support activities, due to their large amount of armaments and ability to engage air and ground targets. This function is currently performed by helicopters of smaller size and with low firepower, which could be replaced by more modern ones, specific for this purpose, thus ensuring better performance in the execution of such activities.

Considering that the models of existing helicopters used in the main Armed Forces of the world can be analyzed in the light of several criteria, whether qualitative or quantitative, this paper applied the AHP-TOPSIS-2N method to support the decision-making process in the classification of attack helicopters.

\section{Research Design/Methodology}

For the feasibility of the analysis, the only information available in the manuals of helicopter manufacturers was used. The criteria chosen after consulting these documents were: Maximum speed (C1); Reach (C2); Maximum payload capacity (C3); Main gun (C4); Amount of main gun ammunition (C5); Number of rockets (C6); Number of air-toground missiles (C7).

To compose the group of alternatives, six helicopter models were chosen, among the most used in the world's Armed Forces: T129 ATAK - Turkish Aerospace, Mi-35M - Russian Helicopters, Ka-52K Katran - Russian Helicopters, HAD Tiger - Airbus, AH-64E APACHE - Boeing, and AH-1Z VIPER - BELL.

Figure 1 illustrates the hierarchical structure of the problem. 
ISAHP Article: A Style Guide for Individual Papers To Be Submitted to the International Symposium of the Analytic Hierarchy Process 2020, Web Conference.

Figure 1 - Hierarchical structure of the problem.

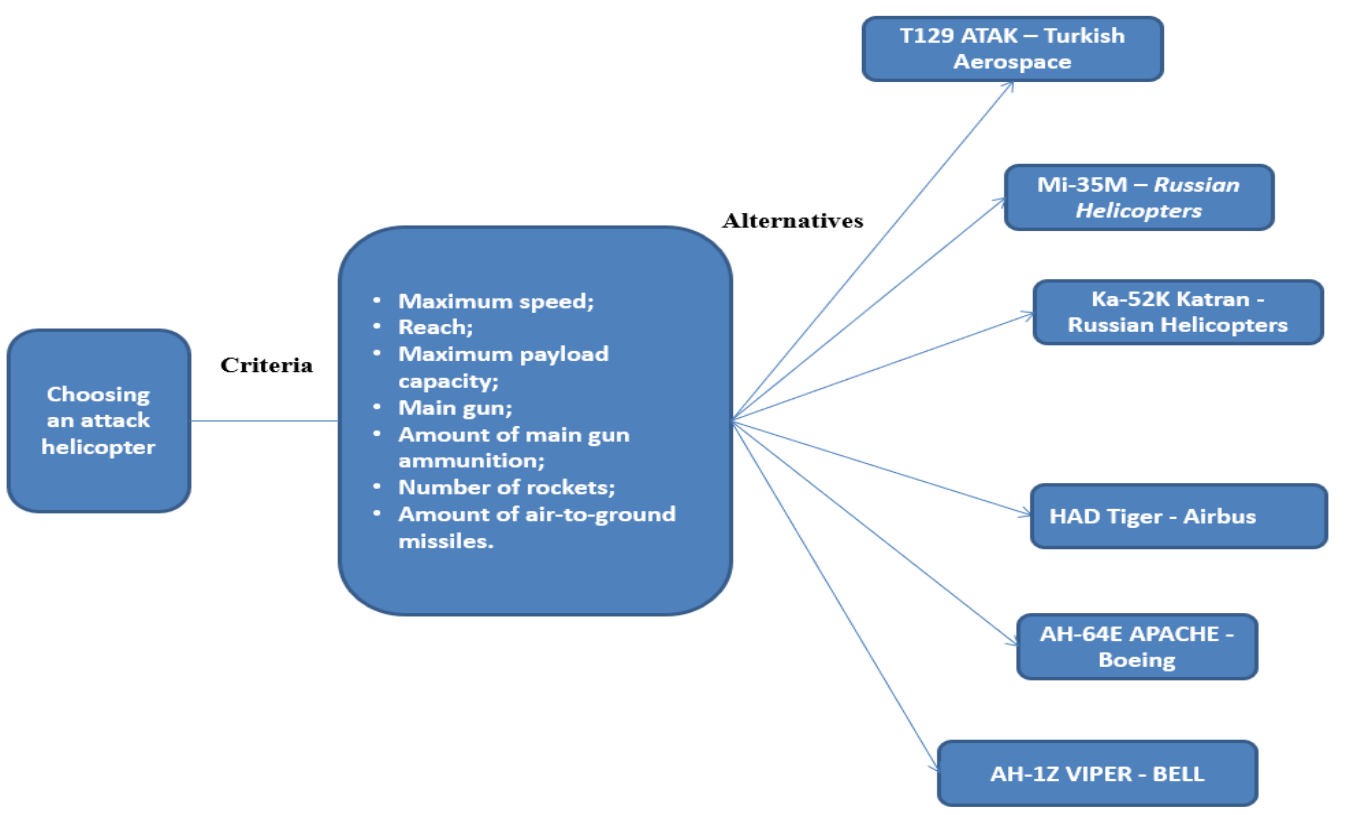

\section{Data/Model Analysis}

Based on the criteria and alternatives established above, the decision matrix is obtained (Table 1).

Table 1 - Decision Matrix.

\begin{tabular}{cccccccc}
\hline & C1 & C2 & C3 & C4 & C5 & C6 & C7 \\
\hline T129 ATAK & 281 & 2710 & 20 & 500 & 76 & 16 & 537 \\
\hline Mi-35M & 310 & 2400 & 23 & 470 & 80 & 20 & 460 \\
\hline BELL AH-1Z VIPER & 370 & 2615 & 20 & 650 & 76 & 16 & 485 \\
\hline Ka-52K Katran & 300 & 3300 & 30 & 460 & 80 & 12 & 460 \\
\hline Tiger HAD & 271 & 2030 & 30 & 450 & 68 & 8 & 740 \\
\hline AH-64E APACHE & 279 & 2835 & 30 & 1200 & 76 & 16 & 476 \\
\hline
\end{tabular}

After applying the AHP-TOPSIS-2N hybrid modeling, the following result was obtained (Table 2).

Table 2 - Final Result.

\begin{tabular}{|c|c|c|c|c|c|}
\hline \multicolumn{3}{|c|}{ 1st Normalization } & \multicolumn{3}{|c|}{ 2nd Normalization } \\
\hline & Classification & Score & & Classification & Score \\
\hline AH-64E APACHE & First & 0,7587 & AH-64E APACHE & First & 0,6852 \\
\hline Mi-35M & 2nd & 0,4791 & Mi-35M & 2nd & 0,5684 \\
\hline BELL AH-1Z VIPER & Third & 0,4421 & Ka-52K Katran & Third & 0,4965 \\
\hline T129 ATAK & 4th & 0,3778 & $\begin{array}{c}\text { BELL AH-1Z } \\
\text { VIPER }\end{array}$ & 4th & 0,4785 \\
\hline Ka-52K Katran & 5th & 0,2809 & T129 ATAK & 5 th & 0,4333 \\
\hline Tiger HAD & 6th & 0,2037 & Tiger HAD & 6th & 0,3204 \\
\hline
\end{tabular}

Analyzing the results obtained, it is observed the existence of three clusters: 
(1) Cluster 1: Includes alternatives with scores between 0.4791 and 0.7587 in the first normalization and between 0.5684 and 0.6852 in the second one: AH-64E APACHE and MI-35M helicopters. It is emphasized that APACHE presented the best ordering in both scenarios, and can be considered the most suitable helicopter to be purchased by the Brazilian Navy;

(2) Cluster 2 - Includes alternatives with scores between 0.2809 and 0.4421 in the first normalization and between 0.4333 and 0.4965 in the second one: BELL AH-1Z VIPER, T129 ATAK and KA-52K Katran helicopters;

(3) Cluster 3 - Tiger HAD helicopter, which achieved the worst performance in both standardization processes.

\section{Limitations}

Another important criterion to make up the model would be the cost of acquiring each helicopter. However, because they are military aircrafts, it was not possible to obtain direct data or reliable estimates of such values, since these parameters are confidential.

\section{Conclusions}

The possibility of evaluating two forms of standardization provides richer and more robust sensitivity analysis, allowing to observe the behavior of alternatives in both scenarios. This characteristic gives more transparency to the decision-making process about a complex problem, such as the object of this article.

The AHP-TOPSIS-2N method proved to be efficient for the proposed analysis, enabling the achievement of the criteria weights, taking into account the opinion of multiple decision-makers, in addition to the robustness generated by the proximity analysis of the Positive Ideal Solution.

It is concluded, therefore, that the method can be used to solve the most diverse real problems of daily life, thus being a very useful method aimed at the contribution of highlevel decision making.

Finally, it is suggested that this model of ordering and distribution in clusters of alternatives using AHP-TOPSIS-2N can be expanded in other applications, serving as a basis for decision making in the most diverse areas of the public and private sectors.

\section{Key References}

Hwang, C.-L., \& Yoon, K. (1981). Methods for multiple attribute decision making. Multiple attribute decision making (pp. 58-191). Mr. Springer.

Saaty, T. L. The Analytic Hierarchy Process. Mcgraw-Hill, New York, 1980.

Souza, L. P. de, Gomes, C. F. S., \& De Barros, A. P. (2018). Implementation of new hybrid AHP-TOPSIS-2N method in sorting and prioritizing of an it CAPEX project portfolio. International Journal of Information Technology \& Decision Making, 17(04), 977-1005. 